Revista de Economia Política, vol. 31, no 2 (122), pp. 238-248 abril-junho/2011

\title{
O neoliberalismo na america Latina
}

\section{DAVID IBARRA*}

\begin{abstract}
Neoliberalism in Latin America. Neoliberalism and globalization had decisive influence in shaping public policies both internal and foreign in Latin America. Less state, trade and market freedoms, social goals subordinated to economic criteria, are part and parcel of the neoliberal utopia. Price stability was erected as the main social objective; import substitution resulted replaced by exports as the main source of growth. The neoliberal net results as applied to Latin America are: less growth, deindustrialization, income concentration and precarious employments. Therefore, countries public policies should try to gain autonomy to use jointly markets and public intervention in a constructive and innovative fashion.

Keywords: neoliberalism; globalisation.

JEL Classification: F02; F43; 054.
\end{abstract}

\section{INTRODUÇÃO}

A globalização neoliberal é uma das transformações históricas de ordem econômica internacional que se expressam sucessivamente no regime colonial, o padrão ouro, o acordo de Bretton Woods e a supressão atual das fronteiras comerciais. Em todos esses esquemas distintos existem, evidentemente, relações de dominação entre os países centrais e a periferia, mas também há acordos indispensáveis para a convivência pacífica e a ordem das transações econômicas entre nações.

O neoliberalismo dificilmente poderia deixar de impor tais requisitos. A diferença é que o faz não somente no campo das relações internacionais, mas também sobre a direção e conteúdo das políticas e instituições internas. Por isso, se integram em normas e regras, que auspiciam determinadas políticas e eliminam os conteúdos em outros modelos, inspirados em planejamentos ideológicos racionalizadores. O estabelecimento dessas normas e suas consequências justificam alterações profun-

\footnotetext{
* Professor aposentado de Economia da Universidade Nacional Autónoma do México. E-mail: dibarra@prodigy.net.mx. Submetido: Agosto 2008; Aprovado: Novembro 2009.
} 
das na vida dos países, particularmente na divisão do trabalho entre o Estado e o mercado ou entre os poderes dos governos nacionais e os da globalização. Consequentemente, o neoliberalismo e a globalização postulam critérios que devem satisfazer os governos - singularmente os do Terceiro Mundo - , quase sempre com escassa ou nula anuência dos cidadãos afetados.

Em consequência, o pós-modernismo neoliberal anuncia o fim da história, dos grandes relatos filosóficos e suas ideologias, e inclusive a do Estado-Nação com suas responsabilidades sociais e seu empenho em cuidar do bem comum, da soberania e identidade nacionais ${ }^{1}$. Em troca, situa a esperança na eficiência de mecanismos automatizados, fora do desejo humano, como o mercado ou estado de direito construído ex professo, em torno do próprio cânone neoliberal. Trata-se de cumprir regras, acompanhadas de incentivos e castigos que, supostamente, afastam os cidadãos de decisões caprichosas e os canalizam à otimização economicista dos seus comportamentos, como se aí esgotassem todos os propósitos humanos.

Em termos propagandísticos, o neoliberalismo difundiu, no Terceiro Mundo, a tese esperançosa de que o jogo livre dos mercados fecharia a brecha do atraso, ao passar não somente pela abertura de fronteiras, como também pela estabilização de preços e contas públicas. Com algum simplismo, postulou-se que o desenvolvimento exportador e de investimento estrangeiro erradicariam a pobreza crônica do subdesenvolvimento, enquanto a difusão automática das melhoras tecnológicas elevaria os padrões de vida e se inverteriam em favor da orientação mercantil das políticas públicas. De modo análogo, sublinhou-se que os mercados abertos e a transparência das transações do governo ou dos particulares colocariam um fim na procura de gastos ou privilégios desmerecidos, isto é, serviriam de antídoto eficaz contra a corrupção ${ }^{2}$.

\section{A UTOPIA NEOLIBERAL}

O neoliberalismo propugna a redução do intervencionismo estatal e do raio de ação da política, ao criar interferências contrárias à liberdade individual e ser uma fonte de corrupção. $\mathrm{Na}$ ordem nacional, o desideratum se finca em conseguir o funcionamento automático da economia e dos mercados, livres de toda distorção governamental ou de cidadãos organizados coletivamente. E, na ordem internacional, concebe-se a globalização como o processo capaz de instaurar a ordem cosmopolita (economicamente eficiente), além da política, como se isso fosse possível.

Em síntese, a utopia neoliberal exalta as virtudes abstratas dos mercados, dos prêmios aos mais aptos, da competitividade, da eficiência, das ganâncias, dos direitos de propriedade, e da liberdade de contratação ${ }^{3}$. Critica, em contrapartida, a

\footnotetext{
${ }^{1}$ Veja-se Fukuyama (1992); Ohmae (1996); Schedler (1997).

${ }^{2}$ Veja-se Buchanan (1980).

${ }^{3}$ Veja-se Nozick (1974); Gray (2000).
} 
intervenção estatal e a própria política, taxando-as de perniciosas e ineficientes. Assim se articulam as teses e se prepara o salto à ideia de que os mercados constituem o miolo de um sistema social ideal, automático, o qual garante o bem-estar e a prosperidade.

Se a isso se adiciona o ingrediente de eleições limpas, tem-se uma combinação ideal de mercados libérrimos e democracia delimitada no eleitoral, como canais de expressão e concretização dos valores supremos das sociedades pós-modernas. Não importa que os processos eleitorais, mais do que servir para confrontar programas e passar o poder a melhores mãos, sirvam para legitimar aqueles que fazem a melhor representação de uma realidade frequentemente imaginada, inexistente, através dos meios massivos de comunicação ${ }^{4}$.

No entanto, há campos de exceção onde o intervencionismo estatal é visto como beneplácito pelo neoliberalismo. Desde as elites empresariais e parte do mundo acadêmico, organizam-se embates políticos e mediáticos ao Estado e, em particular, ao estado benfeitor. Nas nações em desenvolvimento, se vai longe, se alenta uma espécie de revolução institucional encaminhada a dar permanência ao comodismo interno dos países, ante as exigências de ordem político-internacional e, em geral, à construção do estado neoliberal de direito. Em efeito, desde o Estado, muitas funções governamentais se trasladam ex professo a instituições supranacionais ou ao mercado, alargando os direitos negativos às pessoas; no entanto, se reduzem os direitos dos republicanos em participar nas decisões do governo. Inverte-se o conceito tradicional da soberania ao deixar de conceber os interesses forâneos dos próprios, e passar a moldar as economias nacionais aos ditados do mercado global.

Paradoxalmente, e após utilizar expedientes políticos quase sempre autoritários, até conseguir os câmbios legais e institucionais que lhe outorguem posição dominante nos países latino-americanos, o neoliberalismo, agora, abraça o ideal de um mundo sem política, observante escrupuloso do estado de direito, composto por mercados abertos e governos cortados pela ordem econômica internacional. Sem dúvida, a democracia ficaria órfã sem o respaldo e a observância de um estado de direito. Mas, este último há de surgir e transformar-se na expressão genuína da vontade dos cidadãos. Se suas normas nascem da imposição autoritária ou de mecanismos legislativos excluídos, formaram um pseudoestado de direito carente de legitimidade, por violentar o princípio básico de toda democracia, a soberania popular.

\section{AS CONSEQUÊNCIAS DO NEOLIBERALISMO}

Seja como for, a acomodação neoliberal alterou tanto a ordem social interna dos países, como a autonomia estatal ante o exterior ${ }^{5}$. Quanto ao primeiro, a su-

\footnotetext{
${ }^{4}$ Ivan Krastev faz uma análise semelhante com relação as transformações do socialismo ao capitalismo dos países centro-europeus (Krastev, 2004).

${ }^{5}$ Os redesenhos institucionais consistiram no geral no transplante de sistemas forâneos: democracia liberal, mercados abertos, direito nítido de propriedade, limitada intervenção estatal, banca central autônoma etc. Sem dúvida, são instituições importantes em um sistema civilizado de vida como se
} 
pressão do protecionismo, da política industrial e de outras formas de intervencionismo estatal, unida às privatizações e à abertura de fronteiras, alterou radicalmente a distribuição de ingressos, as oportunidades de progresso e a própria estratificação social. Da estratégia do crescimento interno, passou-se a postular as exportações como via de progresso, a estabilidade dos preços e orçamentos e preencheu o lugar ocupado anteriormente pelas metas de geração de emprego; o Estado cedeu o comando ao mercado para fixar a direção e os resultados do manejo socioeconômico.

No domínio da política, as mudanças foram igualmente pronunciadas: o nacionalismo é substituído por uma espécie de cosmopolitismo mal interpretado; se dissolvem as soberanias dos Estados e as entidades nacionais; o presidencialismo autoritário e o corporativismo são substituídos por um regime de divisão de poderes, jogo de partidos e sistemas eleitorais mais transparentes. Como consequência, muito mudaram os valores, os interesses, as instituições, a composição das elites e sem dúvida a distribuição de ingressos.

Com relação a segunda vertente, a abertura de fronteiras e a supressão de travas no investimento estrangeiro mudaram radicalmente as liberdades nacionais ante o exterior. Antes, o ajuste das contas externas cuidava do crescimento e do emprego interno, restringido (quando necessário) as importações, a fim de acentuar as medidas protecionistas; hoje, os desajustes se corrigem, comprimido também as importações, mas através de um mecanismo radicalmente distinto: o de abater o crescimento e o emprego, ou o de acrescentar a dependência com respeito ao investimento estrangeiro ${ }^{6}$. De outra forma, se reinstalam os mecanismos superados pela acomodação do padrão ouro ${ }^{7}$.

Além disso, por si mesmos, os mercados não distribuem com mediana equidade os frutos das redes produtivas e comerciais do mundo. Existem grupos de empresas e países altamente favorecidos, incluindo nações em desenvolvimento, que convivem com outras empobrecidas e atrasadas. ${ }^{8}$ A inserção de Taiwan, Coreia, Vietnã, Irlanda e Finlândia na globalização tem resultado extraordinariamente exitoso. A lição a depreender dessas experiências é complexa. De um lado, que a globalização e neoliberalismo (por mais que tenham ido juntos) não são a mesma coisa e, de outro, que não refletem respostas nacionais idênticas. Portanto, encarar a globalização pode ser feito de diferentes maneiras, por exemplo, com maior ou

\footnotetext{
concebe na pos-modernidade. No entanto, a imitação se levou ao extremo ao centrar-se nas formas, mais do que nas funções. Estas últimas podem ser realizadas de distintas maneiras, de preferência às que geram menos violência na história de cada país. Ao mesmo tempo, se esquece o longo processo evolutivo de conseguir a aceitação social e a consolidação com as novas instituições. Entre 1982 e 2006, mais de $50 \%$ do articulado constitucional - fonte principal do marco institucional - teve que ser modificado com o fim de abrir cabível formal na reforma neoliberal do México. (Veja-se Rodrik (2003); Rodrik et al. (2002); Chang (2004); Ibarra (2005a); Ibarra (2005b).

${ }^{6}$ Veja-se Williamson, J. (1990); Ibarra (2005c).

${ }^{7}$ Veja-se Ibarra (2006a).

${ }^{8}$ Veja-se CEPAL (vários números), Panorama de la Inserción Internacional de América Latina y el Caribe, Santiago de Chile.
} 
menor intervenção governamental, ou deixando tudo, passivamente, às reações espontâneas do mercado. Na América Latina, o insuficiente ativismo exportador marca o retorno à velha especialização na venda de artigos primários - produtos agropecuários, minerais, energéticos, máquinas simples -, enquanto se perde terreno e competitividade, na colocação de manufaturas ou serviços, onde se encontra um avanço tecnológico de caráter mundial.

\section{CONSEQUÊNCIAS PONTUAIS DO NEOLIBERALISMO}

Entre 1975 e 2003, período típico do predomínio neoliberal, a taxa de crescimento per capita mundial, além de polarizar-se entre as zonas prósperas e regiões atrasadas, caiu, em média, mais da metade em relação ao período de 1950-19759. O desenvolvimento não só tem sido estreitado, mas tem-se tornado mais volátil, mais propenso a contágios, mais inclinado a alargar os anos depressivos e a encurtar os de bonança. Ao mesmo tempo, se amplia a brecha do atraso da África e da América Latina. Desde a década de 1970, os países da OCDE cresceram a um ritmo médio de $2 \%$ anual, enquanto a América Latina apenas o fez a $0.6 \%$ e os países africanos subsaarianos, a $-0,7 \%$.

Outra consequência da globalização e do neoliberalismo se refere ao alargamento à escala universal da brecha entre os marginados e abastados e os países.

Em matéria social, salvo exceções, as políticas deixam de procurar a ampliação do mercado interno, o pleno emprego e a universalização dos acessos aos serviços públicos, como os de saúde ou educação. Por outro lado, através da reforma dos sistemas de aposentadorias e levando-se em conta a focalização na distribuição orçamentária de bens, se procura isentar o fisco das obrigações, transferirem riscos do Estado às famílias e multiplicar as oportunidades de negócios privados.

Em quase todas as latitudes, incluídos os Estados Unidos, se observam escassos avanços em corrigir a desigualdade e, em muitas, a pobreza se torna endêmica ${ }^{10}$. A debilidade das organizações laborais, a falta da representatividade dos regimes políticos e as pressões internacionais estão na raiz dos fenômenos de concentração do poder econômico e político. A queda da participação dos salários no ingresso mundial obedece à alta mobilidade geográfica do capital e suas instituições financeiras de respaldo, ante o raquitismo político em escala global das organizações laborais contrabalançadoras. E, do mesmo modo, incide na incorporação massiva da força de trabalho da China e da Índia no mercado globalizado.

Esses fenômenos exacerbaram as desigualdades do Primeiro Mundo e também as de economias de ingresso médio de lento crescimento, enquanto isso favorece as

\footnotetext{
${ }^{9}$ Os defensores do neoliberalismo atribuem o feito ao término dos impulsos associados à reconstrução das nações devastadas pela Segunda Guerra Mundial. Por contra, seus críticos conduzem como fator favorecedor do neoliberalismo o impacto da ascensão da China e da Índia na economia mundial. As cifras são de Maddison (2003). Ver também Wade (1990).

${ }^{10}$ Veja-se PNUD (vários números), Informe sobre Desarrollo Humano, Nova York; CEPAL (vários números), Panorama Social de América Latina, Santiago de Chile.
} 
povoações pobres dos países emergentes mais dinâmicos, mesmo que estas acentuem as disparidades distributivas. Por sua vez, o fracionamento das políticas sociais no âmbito de cada país, reflete as imperfeições dos sistemas democráticos, ao negar voz e participação efetiva de uma boa parte das povoações nacionais. A abolição de fronteiras está provocando uma intensa transferência de capacidades produtivas dos países desenvolvidos e em desenvolvimento intermediário a nações com mão de obra barata e mercados amplos que encarecem aqueles os empregos industriais melhor mente remunerados e forçam a emigração de mão de obra do exterior ou do setor de serviços, em que os salários e aumentos da produtividade são menores.

$\mathrm{O}$ paradigma em vigor conduz inevitavelmente à precarização dos direitos laborais. Conforme a OIT, na região latino-americana, de cada três empregos criados na década de 1990, dois correspondem ao setor informal e, de cada 100 novos postos de trabalho, 83 eram referentes ao setor de serviços, sendo que, $55 \%$ dos novos postos de assalariados careciam de proteção social ${ }^{11}$.

A decomposição do mercado laboral tem significativo reflexo na distribuição regressiva dos ingressos, no conjunto de países latino-americanos. Durante o período 1990-2005, o produto real por habitante cresceu pouco, em razão do 1,3\% anual, mas as remunerações dos assalariados se expandiram menos ainda, 0,6\% ao ano. A escala universal dos custos gerados pela acomodação do neoliberalismo tem sido colocada nos ombros dos trabalhadores, mulheres e marginalizados. Os pactos sociais se estreitam ou se convertem em letra morta. Os sindicatos se debilitam, as afiliações diminuem, muitos são alvos da corrupção. Em termos econômicos e políticos se insiste (com sucesso) na instauração de políticas de desregularização e flexibilidade das normas protetoras do trabalho, sem oferecer quase nada em troca da supressão dos direitos adquiridos.

\section{AS REAÇÕES AO NEOLIBERALISMO}

Como reação natural, desde os primórdios da utopia neoliberal, apareceram resistências e transtornos políticos de envergadura, manifestos claramente nos movimentos guerrilheiros latino-americanos. Ao longo da região, seguem-se multiplicando desajustes sociais recorrentes - seja criminalidade, narcotráfico ou a simples falta de representatividade dos partidos políticos -, não alheios à passividade dos governos em atacar suas raízes. A mudança democrática segue infestada de problemas ainda não resolvidos em muitos países.

A prelação outorgada a criar as instituições de mercado sobre as da democracia substantiva, conforme as estipulações do Consenso de Washington, gerou sérios desequilíbrios na vida social da região. Em essência, as decisões fundamentais às estratégias econômicas e sociais devem ter ficado praticamente excluídas das decisões integradoras dos poderes executivo e legislativo. Daí, a raiz das repetidas crises dos partidos políticos latino-americanos, e de sua escassa representatividade. A democracia eleitoral requer o fortalecimento das conquistas do jogo de partidos;

${ }^{11}$ Veja-se OIT (2000), Panorama Laboral 2000 de América Latina y el Caribe, Lima, Peru. 
contudo (e paradoxalmente), lhes põem empecilhos, em se tratando de abordar o debate dos temas socioeconômicos fundamentais.

Produziu-se uma sorte de estratificação social que lesa a muitos e beneficia a poucos. A democracia, ao desterrar o autoritarismo latino-americano, não chegou com a bandeira da igualdade, mas sim marcou o triunfo de elites nacionais excludentes, aliadas a empresas e grupos forasteiros. A associação entre o neoliberalismo e os valores da democracia, se mostra, portanto, como uma relação frágil, frequentemente encontrada. Os desequilíbrios entre a reforma econômica e a política dão origem a uma transição inacabável, em que sempre ficam pontos soltos, fonte de renovado descontentamento social.

Ainda não há crise da democracia, apesar de já haver, sim, erosão dos sistemas políticos instaurados no último quarto do século passado. De um lado, o reconhecimento dos custos adaptativos às profundas mudanças empreendidas, faz com que se mantenha algum otimismo nos resultados finais do processo. Por outro, não se extinguiram, totalmente, as longas tradições autoritárias da região. Em consequência, os cidadãos dificilmente abrigaram esperanças desmedidas em que o milagre democrático lançaria de súbito, voz e influência aos numerosos grupos excluídos ou geraria prosperidade a todos. Não obstante, ao aprofundar-se a brecha entre os méritos propagados sobre a reforma e o curso das realidades, começam-se a notar sinais de descontentamento, assim como riscos de que a transição política e econômica reverta a situação a um autoritarismo franco, ou a conduza a um autoritarismo brando, mas não por isso menos disposto a determinar sem consulta as orientações básicas das políticas públicas.

Há enfado quanto à politicagem que se faz, paulatinamente, de uma transição interminável que é vazia de conteúdo legitimador à democracia. De modo consciente ou inconsciente, muitas respostas cidadãs se dirigem a recobrar a supremacia da política sobre os ditos de uma economia surda às demandas sociais, a fim de ir além da democracia eleitoral ${ }^{12}$. O conflito já não é propriamente entre direitas e esquerdas, mas sim entre a defesa incondicional de um estado de direito - construído desprovido de democracia - pelo conservadorismo neoliberal e pelo rechaço popular a muitas elites nos governos, imunes ao cidadão sobre seu modo de estabelecer as prelações públicas. Em outras palavras, as tensões políticas frequentemente oscilam entre a desconfiança dos grupos dominantes que a democracia conduzir devido ao populismo irrefreável, e a desconfiança cidadã em direção a elites somente em aparência democráticas, contudo frequentemente distorcidas da realidade social e defensoras de privilégios inaceitáveis.

Em tal situação, países e governos começam a corrigir traços de ordem neoliberal, com o intuito de recobrar a autonomia que lhes permite atender às pressões cidadãs em ascensão. Sem dúvida, aqui existe a possibilidade de levar o pêndulo da radicalização política muito além. Na realidade, há um duplo risco às imperfei-

\footnotetext{
${ }^{12}$ Segundo enquetes do Latinobarômetro, somente $20 \%$ da população latinoamericana confia nos partidos políticos, $25 \%$ o faz com as legislaturas e um terço com o sistema judicial. Fenômenos análogos se reproduzem em muitos outros países, inclusive com virulência, que parece reverter a onda democratizadora ressaltada por Huntington (1991); Diamond (2008).
} 
tas democracias latino-americanas: o de caminhar em direção às autocracias populistas, somente em aparência sensíveis às demandas sociais e o de ir em direção a democracias administradas, seja por via da manipulação, ou por repressão, como já vem ocorrendo em alguns países. Em ambos os extremos, far-se-ia enganoso o pluralismo de valores e interesses do genuíno jogo democrático.

No sentido positivo, vale constatar que os países em desenvolvimento mais bem-sucedidos na globalização são aqueles que impulsionam políticas industriais, promovem o fomento estatal ao desenvolvimento, acentuam o controle nacional sobre os recursos estratégicos (energéticos, por exemplo), regulam cuidadosamente o investimento e os fluxos da economia estrangeira e, sobretudo, fortalecem as instituições de segurança social e a participação cidadã nas decisões coletivas. Em tese, os que antepõem ou equilibram melhor os interesses nacionais, ante os de ordem econômica internacional e os que se apartam da pureza dogmática neoliberal. A América Latina começa a recorrer esse caminho. As políticas emancipadoras que trabalhosamente tomam corpo são repostas ainda que tardiamente (porém necessárias), ante as promessas fracassadas do neoliberalismo, singularmente nos países que mais se apegaram aos termos do Consenso de Washington. Começam-se a estabelecer políticas cambiais ativas, controles dos fluxos financeiros externos, estratégias fiscais contracíclicas, políticas industriais de fomento. Por sorte, já é ultrapassado confundir o atual, o inovador, o moderno, com formas retrógradas de ação que, em dado momento, foi preciso desterrar da nossa história.

Trata-se de esforços esperançosos para alterar a direção das ações governamentais, e também no sentido de contribuir para corrigir tendências e desequilíbrios de ordem universal. Até muito recentemente, a integração de redes transnacionais de produção e intercâmbio, a formação de mercados de dimensão mundial, bem como a multiplicação dos bens de consumo foram os objetivos principais e quase únicos do investimento e de uma investigação tecnológica crescentemente privatizada. Em contraste, costumava-se outorgar prelação menor aos mais significativos problemas da humanidade: a fome e a desnutrição, a enfermidade, a ignorância, a provisão de energia limpa, a contenção da destruição ecológica.

\section{REFLEXÕES FINAIS}

A utopia neoliberal representa a tentativa mais abarcadora e decisiva por voltar o "relógio político" para trás, suplantar o velho programa humanista do Iluminismo ou os impulsos progressistas nacionais, bem como deixar de lado as responsabilidades do Estado ou da democracia, aqui entendida em seu sentido republicano. Mesmo assim, suas teses se disseminam com extraordinária rapidez no mundo, se comparadas com qualquer outra experiência análoga. Crise, apuros e pressões internacionais sem número, ao menos na América Latina e África, levam os países a liberar os mercados, reduzir o papel do Estado, assimilar desigualdades sociais não suspeitadas, desestabilizar a ordem, as hierarquias e as prelações nacionais, em uma palavra a limitar as opções à ação coletiva. E mais, as teses neoliberais representam uma mudança radical, frequentemente irrealista, na maneira de visua- 
lizar os problemas do desenvolvimento e as explicações justificatórias das políticas a serem instrumentadas ${ }^{13}$.

Boa parte das mudanças implantadas é fruto de um intervencionismo marcante que, uma vez consolidado, quer-se manter sem nenhuma alteração. Por isso, hoje em dia é arriscado dar vazão ao jogo da política e precisa-se demarcar a esfera democrática do espaço público. O alcance das estratégias econômicas e sociais, mais que na participação cidadã aberta, faz-se conveniente em cenáculos fechados, sujeitos às orientações e às restrições impostas pelo cânone neoliberal e as instituições internacionais. À democracia, somente lhe é oferecida alguma limpeza eleitoral e alternância política, como meio de atender o descontentamento nascido da nova ordem econômica, de suas disparidades distributivas e da débâcle institucional pós-moderna. À política, lhe é atribuído o limitadíssimo papel de compensar, até onde forem possíveis, os custos sociais das reformas neoliberais, oferecendo, não soluções, mas sim, como foi dito, a simples alternância no poder.

O encurralamento neoliberal da política e do debate democrático é o outro rosto que se vê da tentativa de minimizar o Estado-Nação, com a transferência de funções ao mercado interno ou ao internacional e com suas significativas restrições aos direitos coletivos ${ }^{14}$. Tais fatos concentram privilégios e rendas, excluem a voz das maiorias nas decisões e forçam a transformação conservadora do próprio Estado, ao colocá-lo mais e mais a serviço de objetivos elitistas, próprios ou forâneos. Formalmente, nossos países são democráticos, mas com uma democracia sem opções reais significativas.

Como foi dito, os grupos dominantes na América Latina e muitos de seus governos têm por hábito defender incondicionalmente estados de direito projetados ad hoc ou em acordos copulares excludentes. E ao mesmo tempo repudiam ou criticam como populismo inaceitável as garantias sociais modernas, como o seguro desemprego, o acesso generalizado aos serviços de saúde, a renda mínima garantida, por considerá-los inimigos da competitividade, da disciplina do trabalho ou mecanismos redutores dos recursos investíveis.

Mais uma das características da ação neoliberal, consiste em dar vazão à difusão de visões ideológicas distorcidas da realidade ou da história. Todos os males econômicos e sociais, caso do México, se atribuem a erros dos governos anteriores à reforma neoliberal, ainda que os contradiga a comparação das taxas de crescimento ou de emprego e a debilitação de múltiplas instituições de proteção social. A eficiência do mercado e das privatizações são artigos de fé, ainda que o negue a queda geral da produtividade, a crise e resgates bancários, ou os fracassos das privatizações. Acusa-se a PEMEX e seu sindicato, pelo fato de haverem criado um centro de ineficiência e corrupção — sendo por essas razões privatizável —, apesar

\footnotetext{
${ }^{13} \mathrm{O}$ economista brasileiro Bresser-Pereira preparou a primeira crítica ao fundo do Consenso de Washington, o que provocou uma sucessão de artigos dos mais diversos caráter. Veja-se Williamson (1990); Bresser-Pereira et al. (1993); Voo (2004); Stiglitz (1998); Ibarra (2006b); Gore (2000).

${ }^{14}$ Automaticidade do mercado e do estado neoliberal de direito quase fez desaparecer a ação independente dos cidadãos, submetidos às exigências de um sistema onde quase tudo é subordinado. (Veja-se Luhmann, 1998).
} 
de que o refutem suas enormes utilidades antes de impostos e a transferência íntegra das rendas petroleiras para que o fisco faça do México, não um país de energia barata, mas sim um país de baixos impostos. A retórica da eficiência do mercado continua mascarando a ganância de poder por parte do conservadorismo universal, somado ao vernáculo.

O neoliberalismo se apresenta como ruptura no tempo, como o início de uma época radicalmente distinta à organização social anterior; portanto, proclama sua autonomia do passado para ganhar a liberdade de construir novas formas de vida e novas instituições, ao mesmo tempo em que rechaça as comparações históricas em alguma medida, porque não lhe favorecem. Em troca, postula uma utopia universalista, aplicável a qualquer sociedade humana decidida a fechar seu passado e a inaugurar uma época de renascimento economicista. Como no monoteísmo, não se admite, descarta-se, toda competência doutrinária. Esse é o sentido da frase "o fim da história" que anuncia o triunfo do capitalismo neoliberal sobre o socialismo e sobre qualquer outro regime político em que se pudesse pensar.

\section{CONCLUSÕES}

Nas realidades latino-americanas, a subordinação acrítica à nova ordem internacional priva os cidadãos da liberdade republicana de decidirem seus fins coletivos e aos Estados-Nação de usarem sua soberania plenamente. Em matéria de macropolítica - com exceção da limpeza eleitoral —, impuseram-se critérios que estreitam a possibilidade de gerar soluções ou inovações próprias.

Os habitantes de nossos países, somente com grandes dificuldades, poderiam livrar-se da tirania do consumismo e da propaganda ideológica-comercial e, por outro lado, da marginalização e insegurança econômicas. As decisões socioeconômicas fundamentais ficam, em alto grau, excluídas do escrutínio público. Em particular, a política social se esteriliza no esforço focalizador, poupador do gasto público, entretanto incapaz de curar com eficiência mediana a marginalização e o desemprego macroeconômico formal e informal. Como resultado, o sistema social caminha por veredas afastadas do aprofundamento da democracia substantiva.

A aceitação do paradigma neoliberal tem produzido queda no ritmo de desenvolvimento, desindustrialização e reversão dos processos de absorção dos marginalizados, que ainda representam cerca de $40 \%$ da população latino-americana. E mais, quando as economias crescem, a renda se concentra. A macroeconomia em alta proporção tem deixado o mercado devedor, com evasão expressa ou tácita às responsabilidades estatais, de ganhar prosperidade e resguardar mínimos de justiça social. Quanto à microeconomia, pouco a pouco cobra carta de naturalização o critério curto-prazista dos investidores institucionais do Primeiro Mundo - maximização do valor das ações na bolsa -, enquanto se descuidam dos apoios às pequenas e médias empresas, dos investimentos de longo prazo e permite-se a estrangeirização das melhores empresas públicas e privadas.

Em suma, seja em matéria política, institucional, social, macroeconômica ou microeconômico, México - e talvez boa parte da América Latina - vem cedendo ao automatismo dos mercados e aos ferrolhos do estado neoliberal de direito, a 
faculdade de determinar a evolução dos países e a sorte das pessoas. A utopia neoliberal quisera prescindir da ideia vertebral da liberdade humana: a capacidade individual e, sobretudo, coletiva de determinar, construir um melhor futuro para todos. De fato, o neoliberalismo substitui os dogmas do autoritarismo ou da religião, por um dogma civil, mais grosseiro ou mais sutil, porém certamente desumanizado. Portanto, haver-se-á de colocar às claras, mais depressa, as ficções ideológicas que nos envolvem para devolver, o quanto antes, o papel reitor à política. $\mathrm{O}$ mercado nem sempre funciona com sabedoria, nem tem por hábito ver à distância; a intervenção estatal pode errar, mas nem sempre se equivoca quando reflete genuinamente a vontade coletiva. Estado e mercado não se excluem entre si, são instrumentos indispensáveis na tarefa de irmanar democracia e desenvolvimento na supressão paulatina do sofrimento desnecessário de grandes grupos da população latino-americana.

\section{REFERÊNCIAS BIBLIOGRÁFICAS}

BRESSER-PEREIRA, L. C. et al. (1993), Economic Reforms in New Democracies, Cambridge: Cambridge University Press.

BUCHANAN, J. (1980) "Rent-seeking and profit seeking", in Toward a Theory of Rent-seeking Society, Austin: Texas University Press.

CHANG, H. (2004), Rethinking Development Economics, India: Anthem Press.

DIAMOND, L. (2008) "The democratic rollback", Foreign Affairs, 87 (2): 36-48.

FUKUYAMA, F. (1992), The End of History and the Last Man, Londres: H. Hamilton;

GORE, Ch. (2000) "The rise and fall of the Washington Consensus as a paradigm for developing countries", World Development, 28 (5): 789-804.

GRAY, J. (2000), Las Dos Caras del Neoliberalismo, Madrid: Paidós.

HUNTINGTON, S. (1991), The Third Ware, Oklahoma: University of Oklahoma Press.

IBARRA, D. (2005a), Reforma e instituciones, mimeo, México.

IBARRA D. (2005b) "Estado de derecho, constitución e instituciones", Revista de la Facultad de Derecho de la UNAM, tomo LV, No. 243.

IBARRA, D. (2005c) Ensayos sobre Economía Mexicana, México: Fondo de Cultura Económica.

IBARRA, D. (2006a) "El péndulo monetario", em La Reconfiguración Económica Internacional, Facultad de Economía, UNAM, México.

IBARRA, D. (2006b), La reconfiguración económica internacional UNAM, México.

KRASTEV, I. (2004) “Democracy's doubles”, Journal of Democracy, 17 (2): 52-62.

LUHMANN, N. (1998), Sistemas Sociales, Barcelona: Anthropos.

MADDISON, A. (2003) The World Economy, A Millennial Perspective, París: OCDE.

NOZICK, R. (1974), Anarchy, State and Utopy, Oxford: Basil \& Blackwell.

OHMAE, K. (1996) The end of the Nationl-State, Londres: Harper Collins.

RODRIK, D. (2003), “Growth strategies”, NBER Working Paper 10050.

RODRIK, D. et al. (2002), "The primacy of institutions over geography and integration on economic development”, NBER Working Paper No. 9305, Washington.

SCHEDLER, H. (1997), The End of Politics, Londres: Macmillan.

STIGLITZ, J. (1998), More instruments and broader goals, moving towards the Post-Washington Consensus, Wider Annual Lecture, Helsinki.

VOO, W. (2004) "Serious innadequancies of the Washington Consensus", em Diversity in Development, compiladores, Tennissen, J., Fondad, La Haya.

WADE, R. (1990), Governing the Market, New Jersey: Princeton University Press.

WILLIAMSON, J. (1990) "What Washington means by policy reform", em Latin American Adjustment, Institute for International Economics, Washington. 